\title{
DESIGN PARAMETERS CF THE MULTI-BOLTED JOINT.
}

\author{
GABER M.M. SHEHA ${ }^{*}$
}

\section{ABSTRACT}

The multi-bolted jcint is commenly used in various machine design problems, such as the joint between the base and the culumn of the milling machine. The paper deals with the design parameters of the multi-bolted joint and their effect on the joint stiffness. An optimal methematical method to calculate the static joint stiffness has been chosen. The effect of the bolt diameter, number of the bolts to be used, and thickness of the members to be jointer on the magnitude of the normal stiffness of the joint have been anal, ised and discussed. A proposed design diapram for the bolted joint loaded with the normal external force are developed and it can be simply used.

\section{INTRCDUCTIUN}

The function of the bolted joint is to generate the fixation of two or several parts with optimum stiffness. The stiffness of such joints greatly depends on the large number of design parameters. These parameters may be summerized as:

1. Magnitude of the preload and the external load and the relation between them.

2. Number of the bolts to be used and their dimensions.

3. The distance between the bolts.

4. The flange thickness.

5. The compliance of the contacting surfaces.

6. The elasticity of bolt and flange material.

Fig. (1) represent the configuration of the multi-bolted joint, which consists of several sinfle-holted joints. Due to large initial tightening force $\left(F_{v}\right)$, the stiffness of the joint is usually high. Also, the relation between the extornal force (FB) ant elastic deflections, caused by these forces, is close

* Lecturer, Department of Production Engineering and Design, Faculty of Engineering and Technolory, Menoufia University, Shebin El-Koom, Egypt. 
to non-linear, as the external forces are significantly lower than the tightening ones. 'There are many methods have been developed to calculate the static stiffness of a single-bolted joint (view A in Fig.1). The majn recently methods have been reviewed by LEVINA, Z.M. [3], SHEHA, G. $[5-6]$ and PLOCK, $R[4]$. The effect of the distancs between the bolts on the deflection in a tightened foint has been illustrated by the example of the joint of plates of the slideways (Fig.2) on the bed [1-2]. The distribution of the deflection and pressure over the length of the joint is not uniform, being higher in the cross-sections under the bolts ( $\delta_{\max }$ in Fig. 2-b) than in those between them. The rate of this uneven distribution depends on the thickness ( $h f$ ) of the way and the distance (L) between bolts. The mean pressure derived by the bolt tightening stress in the joint is assumed to be $30 \mathrm{kp} / \mathrm{cm}^{2}$. It is cleare that, the distrotions of the ways are not large if the distance between the bolts is small. As soon as the value of (L) exceeds a predetermined value determined by the size of the thickness $\left(h_{f}\right)$, the value of the distorsion sharply increases. But, this diagram has not been considered the bolt diameter, number of bolts and the magnitude of the joint stiffness. These parameters hive not been studied. Reference [5] has been derlved a mathematical model to calculate the static stiffness of the multi-bolted joint. Also, this models have not been considered the effect of the bolt-distance.

It is apparent that there is no comprehensive study for the relationship between the joint stiffness and the main joint parameters such as bolt-liameter; number of bolts to be used; flange thickness and the bolt distance. Therefore, a great deal of this work was done to decide the optimal calculation method for the stiffness of the bolted joint, wich enable to establish a proper design diagram. The effect of the joint design parameters on the magnitude of the joint stiffness was also investigated.

\section{2•OPTIMAL METHOD TC CALCULATE}

\section{THE JOINT STIFFNESS.}

The correct determination of the bolted joint stiffness is nf extreme importancs in the design of joint elements (See Fig.1) There are many trails for approximate determination of the static ioint stiffness based either on experimental or theoretical approaches. The most important of these methods are due to:

1.LEVINA, Z.M.[3] who suggested the following formulae to calculate the bolted joint stiffness;

$$
F_{s z}=C_{2} \frac{C_{3}+\frac{A k_{k}^{m}}{\alpha \cdot m}\left(F_{v}-F_{B}+F_{s z}\right)^{l-m}}{c_{3} \frac{A_{k}^{m}}{\alpha \cdot m}\left(F_{v}-F_{B}-F_{s z}\right)} \cdot\left(F_{B}-F_{s z}\right) \ldots .
$$




\section{\begin{tabular}{l|l}
$M D-1$ & 3
\end{tabular}}

2. SHEHA,G. [5-6] who derived the following equation to estimate the value of the single-bolted joint.

$$
C_{J}=C_{2}+\frac{F_{v}-F_{R}}{\frac{F_{v}^{-F_{R}}}{C_{3}}+\frac{\alpha}{A_{k}^{m}}\left(F_{v}^{m}-F_{R}^{m}\right)}
$$

3. PLOCK, R. [4] who suggested the following equations to calculate the joint stiffness.

$$
\begin{aligned}
& \left(\frac{1}{C_{3}}-\frac{1}{C_{2}}\right) F_{v}-\frac{\alpha}{A_{k}^{m}}\left(F_{v}\right)^{m}=\left(\frac{1}{C_{3}}-\frac{1}{C_{2}}\right) F_{R}-\alpha\left(\frac{F_{R}}{A_{k}}\right)^{m}-F_{B} / C_{3} \ldots \\
& \delta_{B}=\frac{F_{R}}{C_{3}}-\alpha\left(\frac{F_{R}}{A_{k}}\right)^{m}-\frac{F_{v}}{C_{3}}+\alpha\left(\frac{F^{\prime}}{A_{k}}\right)^{m} \\
& c_{J}=F_{B} / d_{B}
\end{aligned}
$$

The three methods can be solved by the j.teration calculations using the computer. The program has been developed to include the following main elements:

1. Summery of the required deta.

2. Solving of the equations of the three methods to determine the value of the static stiffness of the joint ( $\left.C_{j}\right)$.

3. Checking of the maximum static and dynamic stresses in the joint [6].

4. Summery of $t$ he results.

To decide the best method to cal culate the joint stiffness, which gives the designer the proper and more safe joint design, the comparison between the three methods may be useful. Fig.3 represent a relation between joint stiffness $\left(\mathrm{C}_{\mathrm{J}}\right)$ and the preload on the bolted joint $\left(F_{y}\right)$. The curves have been made based on the follouring main data:

$$
\begin{aligned}
& \mathrm{C}_{\mathrm{s}}=107 \mathrm{~K} / \mu \mathrm{m} ; \mathrm{A}_{\mathrm{k}}=122 \mathrm{Cm}^{2} ; \mathrm{C}_{3}=532 \mathrm{~K} \mathrm{p} / \mu \mathrm{m} \\
& \alpha=0.8 ; \mathrm{m}=0.5 ; \mathrm{F}_{\mathrm{v}}=100 \mathrm{C}, 2000,3000 \mathrm{~K} \mathrm{~K} \text { and } \\
& \mathrm{F}_{\mathrm{B}}=40 \mathrm{H}, 600,800 \mathrm{~K}_{\mathrm{p}} .
\end{aligned}
$$

The curves have been presented that, in all methods the increasing of the prelcad ( $\left.F_{v}\right)$ produce preatly increasing in the joint stiffness. The effect of the external load (FB) on the joint stiffness has heen made in $(F 1 g .4)$. The curves show also the deviation in the calculated joint stiffness according to LEVINA-; SHEHA - and PLCCK-methods. It has been shom that the PLOCKMeihou gives the best stiffness value, which can be used safely by the designer. 


\section{EFFECT OF THE DESIGN PARAMETERS ON THE STATIC JOINT STIFFNESS.}

To represent the systematic variation between the stiffness of the multi-bolted joint and their main design parameters (bott diameter; holt distance and flange thickness), the following assumptions may be useful to use:

1. The two connected members are to be simple geometry with the length $1 \mathrm{~m}$. and thickness $34,41.3$ and $60 \mathrm{~mm}$.

2. The external load is a pure normal force with magnitude $10000 \mathrm{~K}$.

3. Constant cross-section of the bolts to be used ( $\mathrm{n} \cdot \mathrm{A}_{\mathrm{s}}=1575 \mathrm{~mm}^{2}$ ).

4. The angle of the effective frustum cone $\beta$ is 45,50 and 55 derree.

5. Material : St. 50 for the two connected members and St. 42 for the screw bolts to be used.

6. The external load is devided equally on the bolts to be used in the joint. Thereoff, the total normal joint stiffness can be calculated using the following formula:

$$
c_{z}=\sum_{i=1}^{n}\left(c_{J}\right)_{i}
$$

Fig. (5-a) shows the effect of the number of bolts to be used on the magnitude of the normal deflection at a constant flange thickness ( $h_{f}=60 \mathrm{~mm}$ ) The points $a$ and $b$ have the bolt arrangement $n=7$ bolts; $M 20$ and $n=15$ bolts; $M 14$ respectivily; distributed on $1 \mathrm{~m}$. flange length (See Fig. 5-b). The optimal tendence of the calculated deflection has large number of bolts with small bolt diameter. This result meant that to produce high joint stiffnesis must be used the large number of bolts with small bolt diameter. But the designer should first of oli decide the minimum required distance between the two bolts.

Fif. (6) represent the relationship between the number of bolts, minimum bolt distance and the flange thickness. In the bolted joint, the bolt distance and the flange thickness are usually related with the effective frustum cone (angle $\beta$ ).

Fig. $(6-a)$ represents the relationship between the design parameters through the ancle $\beta$. Thereoff, the reduction of the flange thickness (hf) requjres large number of bolts (compare between casa a and cas b), while at constant number of bolts the bolt listance becomes high with higher angle $\beta$ and the reduced flange thickness (compare between case a and case c).

It is clear that, the systematic variation of the parameter $\beta=45$, 50 and 55 degree leads to proportional relationship between the calculated normal deflectiond, the flange thickness (hf) and the number of holts $(n)$. Also, at the large number of bolts, reduced flange thickness and owing tc the joint configura tion the magnitude of the normal deflection can be estimated, (see Fig. 6-a). Thus, the designer may use $\beta=45$ degree to calculate the joint stiffness $\left(C_{z}\right)$. These value gives the optimal 


\section{THE DESIGN DIAGRAM}

To construct a diagram for designing the multi-bolted joint the relationship between the normal stiffness and the joint design parameters should be defined at first.

Fig. (7) shows the magniture of the normal stiffness $\left(C_{2}\right)$ with respect to the joint design parameters. The curves of the diagram have been calculated accordine to the optimal condition( Plockmethod with $\beta=45$ degree). In this case the minimum bolt distance can be calculated as (See Fig. 1):

$$
L=1.4 d s+2 h_{f}
$$

Also, the joint stiffness $\left(C_{z}\right)$ has been calculated using the equations $(4,5,6$ and 7$)$.

The designer can easily, use the diagram to compare the magnitudes of $\mathrm{C}_{2}$ which related to the design variations. Also, for the required stiffness $C_{z}$ with defined flange thickness $h_{f}$, the desioner can use the diagram to determine the bolt diameter and the number of bolts to be used. Thus, the designer can decide the proper joint parameters without any weakening positions between the bolts.

\section{CONCLUSIONS}

The optimal method to calculate the magniture of the bolted joint stiffness has been decided by the comparison between the mathematical meth ods of TIEVINA, $Z, M$; SHEHA, G. and PLOCK, R. The main design parameters of the joint have been discussed. The PLOCK-Method with frustum cone $\beta=45$ degree is the optimal condition to designing of the foint.

A simplified design diagram of the bolted joint loaded with the normal external force has been developed based on the optimal condition. The designer can use the proposed design diagram to decide directly the main joint parameters such as bolt diameter to be used, thickness of members to be jointed and number of bolts to be used.

\section{ACKNOWLEDGEMENT}

The author wishes to express his sincere gratitude to Prof.Dr. Eng. A.A.NASSER, Dean of Faculty of Eng. \& Tech., Menoufia University for his continuous helpfull and great interest throughout this work. 
\begin{tabular}{|l|l|}
\hline$M D-1$ & 6 \\
\hline
\end{tabular}

SECOND A.M.E. CONFIRFNCE

6 - 8 May 1986 , Cairo

\section{NOTATIONS}

A ${ }_{3}$ : Tensile stress area of screw bolt.

$A_{k}$ : Contact area.

$\mathrm{C}_{2}$ : Stiffness of the bolt under external load.

$\mathrm{C}_{3}$ : St1ffness of ths members under externa 1 load.

$\mathrm{C}_{\mathrm{J}}$ : Static stiffness of the single-bolted joint.

$c_{s}$ : Stfffness of screw holt.

$\mathrm{C}_{\mathrm{z}}$ : Normal stiffness of the mult1-bolted foint.

$d_{s}:$ Mafor bolt diameter.

$F_{B}$ : Total external tension load on joint.

$F_{R}$ : Resultant load on the members to be jointed.

$F_{s z}$ : Portion of bolt from the extarnal load $F_{B}$.

$\mathrm{F}_{\mathrm{v}}$ : Preload on holt due to tightening.

$h_{f}$ : Thickness of the members to be jointed:

I : Bolt distance.

n : Number of the bolts to be used in the joint.

$\alpha, m$ : Factors depending on the properties of material and suríace finish.

$\beta_{\mathrm{B}}$ : Anple of the effective frustum cone.
$\delta_{\mathrm{B}}$ : Joint deflaction under the external load.

\section{HEFERENCES}

1. Back, N. "Deformatlons in Machino Tool Joints", Ph.D. Thes1s, U.M.L.S.T., 1972 .

2. Back, N. Burdekin, M. and Cowley, A. "Reviow of the Research on Fixed and 311 inf Jolntg", 13 th Int. M.T.D.R. Conf. Macm1118n, 1973 .

3. Levina, Z,M. "Hesearch on the Static Stiffness of Jo1nts in Machin' Tools. "Proc. 8 th N.T.I.K. Conf., 1967.

4. Plock, R. "Untersuchung and Berechnung des elastostatischen Verhaltens von ebenen Mehr-Schraubenverbindung". Diss. TH. Aschen, 1972 .

5. Shehs, G. M.M. "Aufbau eines Katalogues zur statischen Auslerung. von verschraubten Verbindungsstellen". Thesis, $T U=D r e s d e n$ G.D.K, 1982.

6. Shena, G. MM. "A Jtmplified Desifn Method of a Tension Logded Bolted Jo1nt. "AMSE' Period1cal, Vol. 1, No 4, P.13-34 France, 1984. 

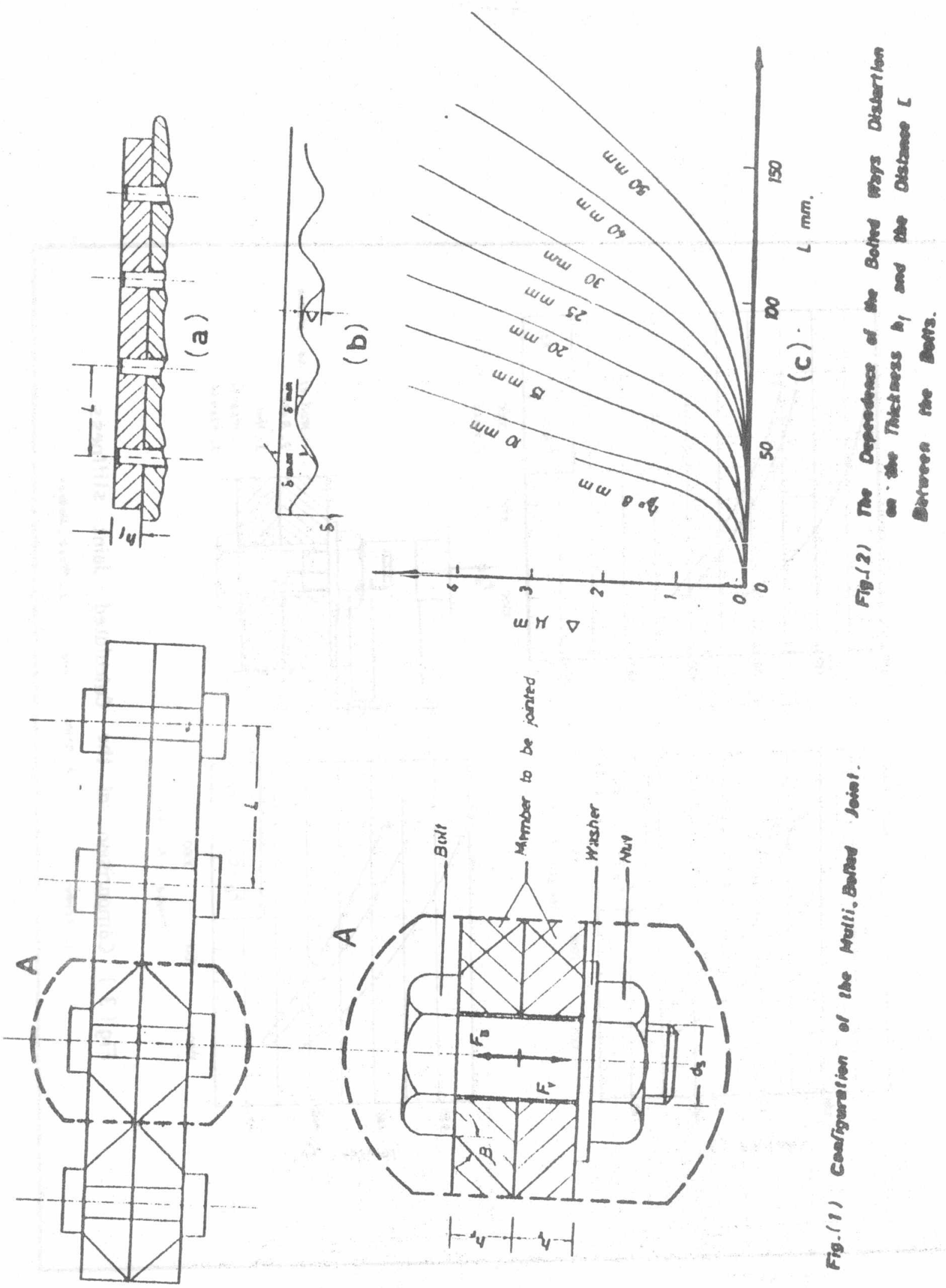

8

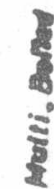

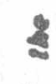

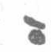

5

$\frac{1}{10}$ 
\begin{tabular}{|l|l|}
\hline$M D-1$ & 8 \\
\hline
\end{tabular}

(BICONI) A.M.l. CONFI:RENCE

6. - 8 May Lo86, diriro

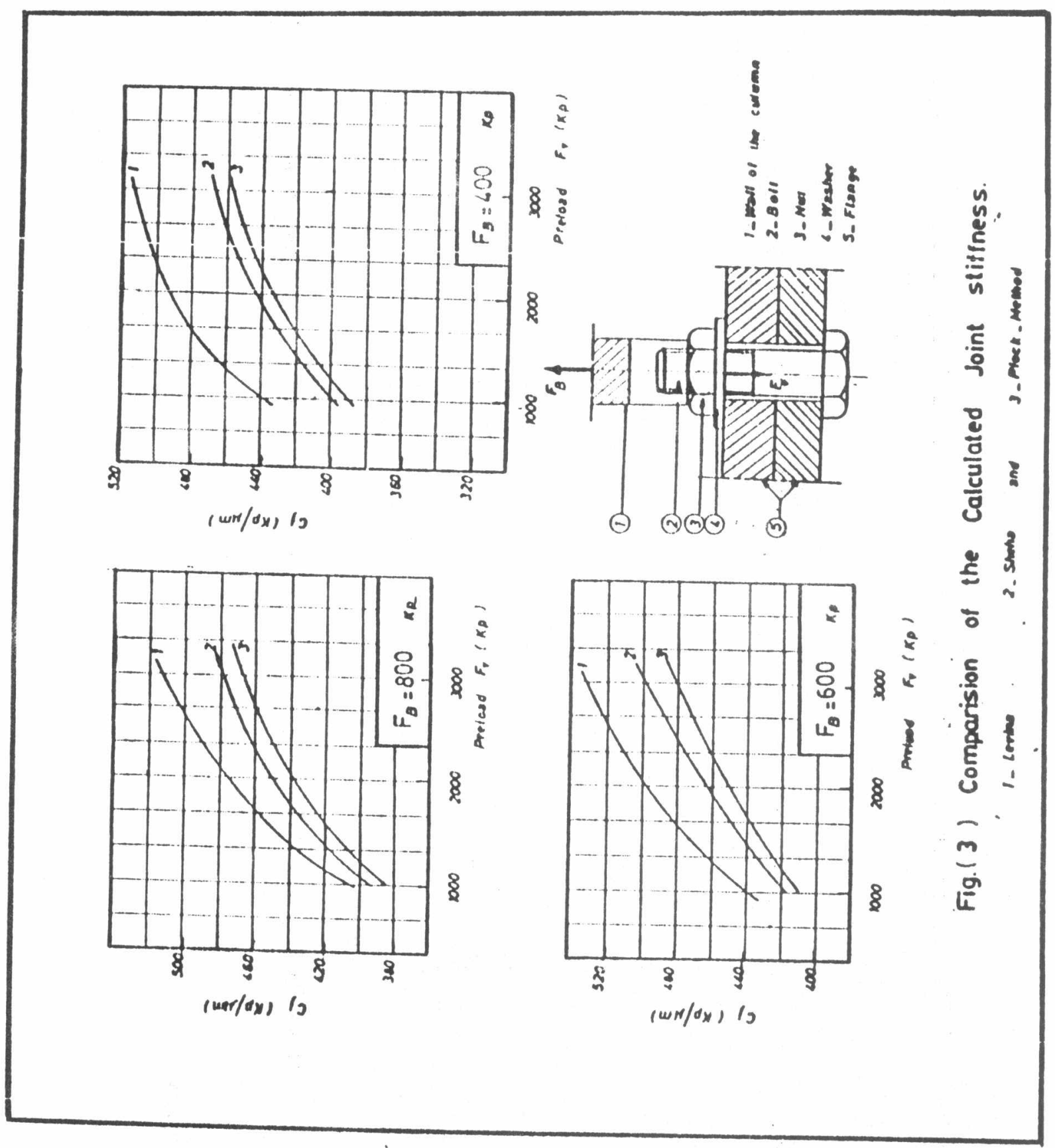


\begin{tabular}{|l|l|}
\hline$M D-1$ & 9 \\
\hline
\end{tabular}

GFOND A.M.E. CONFIIRENCE

6. - R May 1986, (iviro

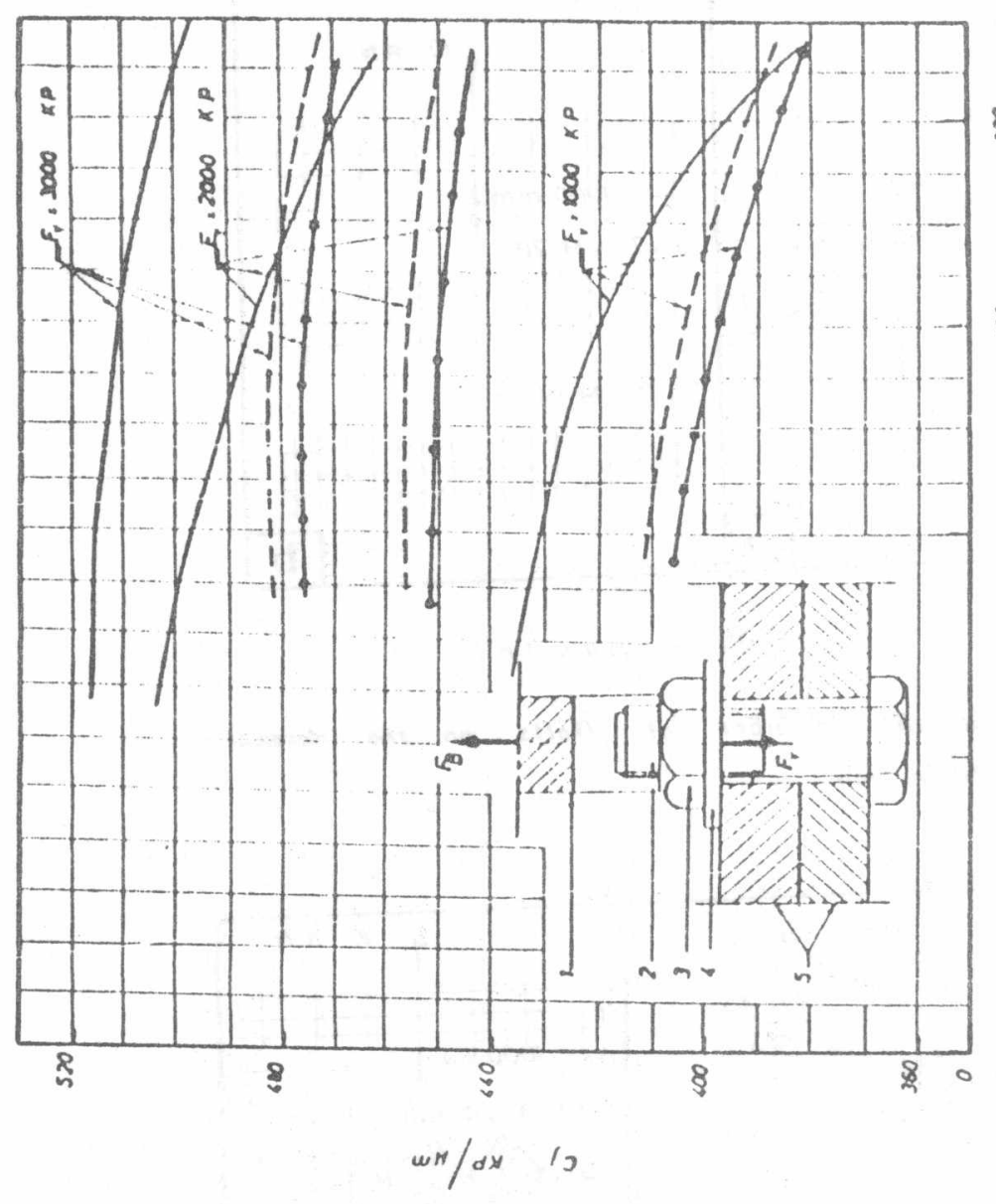

早

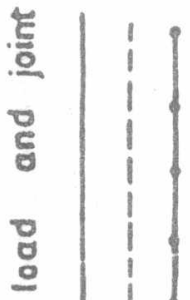

4

\%

$\therefore$ है

\$.

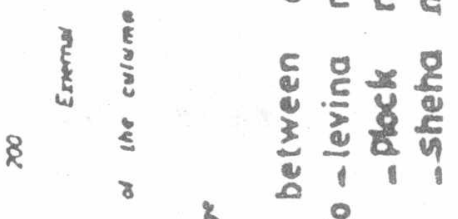

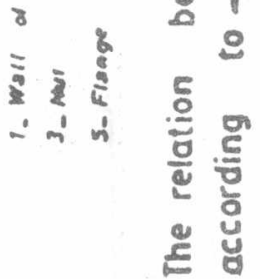

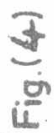




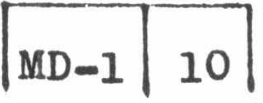

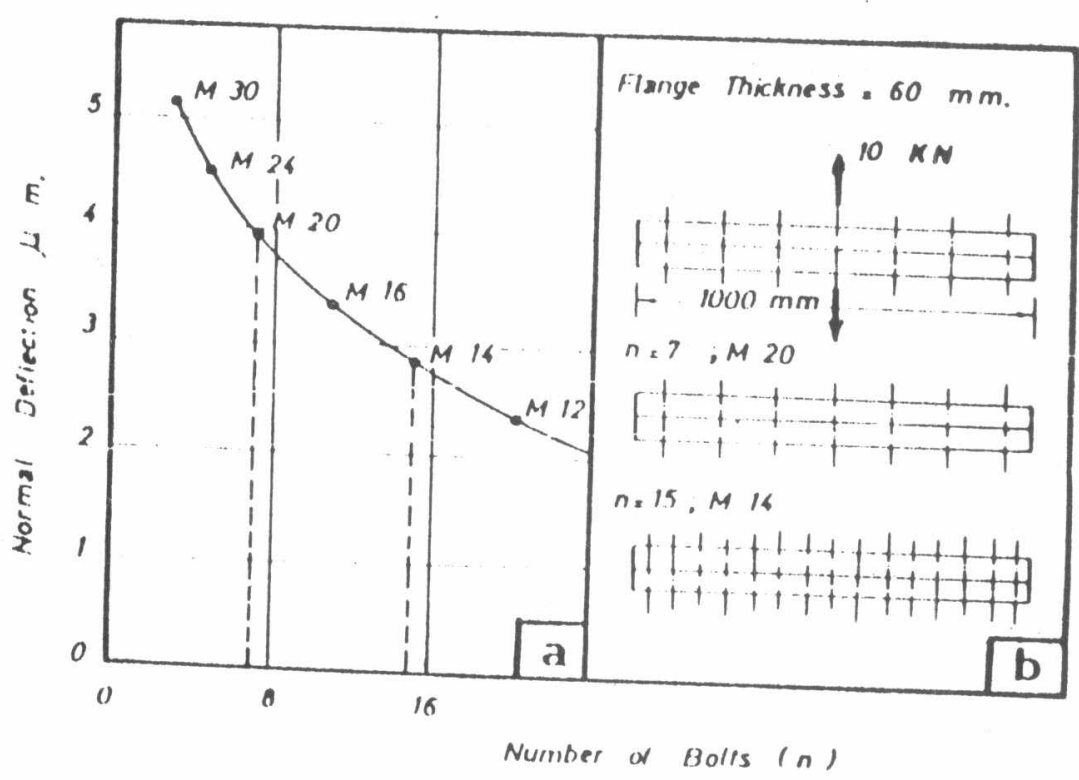

Fig. (5) Elfect of the Nivinber of Bolls on the Manenel joine Deflection.

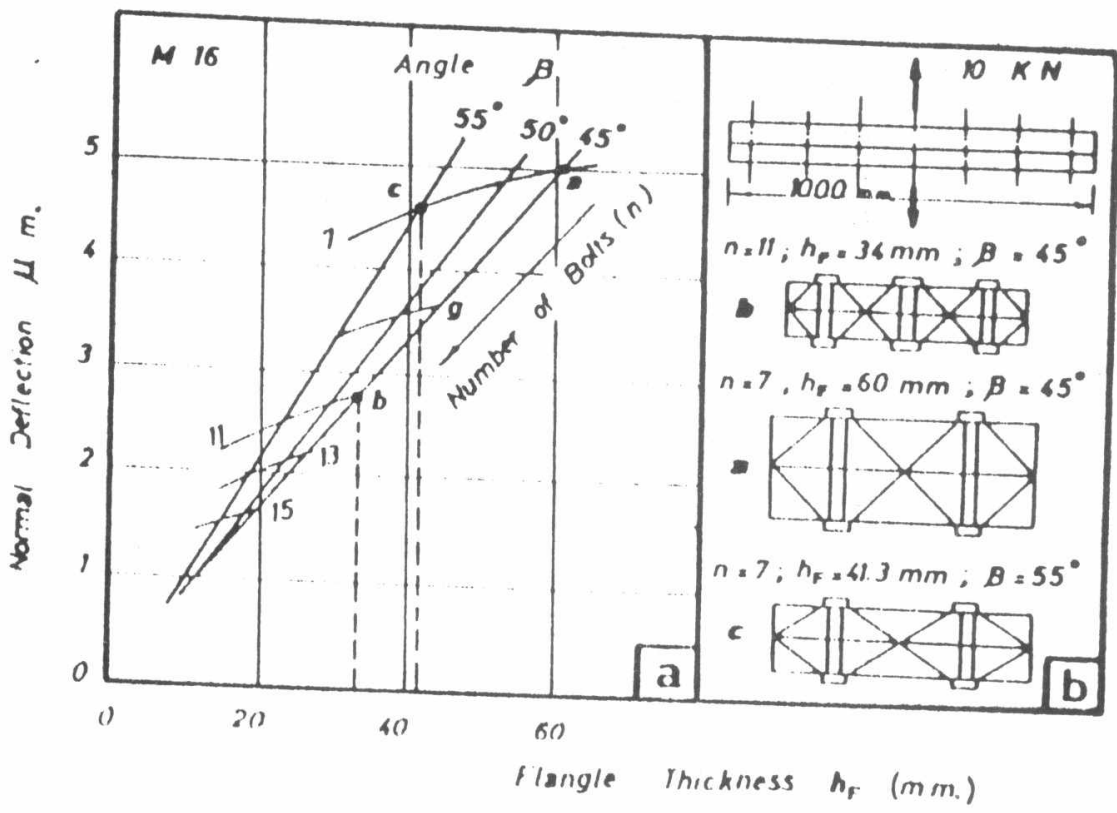

Fig. (6) fllect of the Number of Bolls, Boll Disfance and Flange Ihickness on the Normal Defurction of the Joint. 


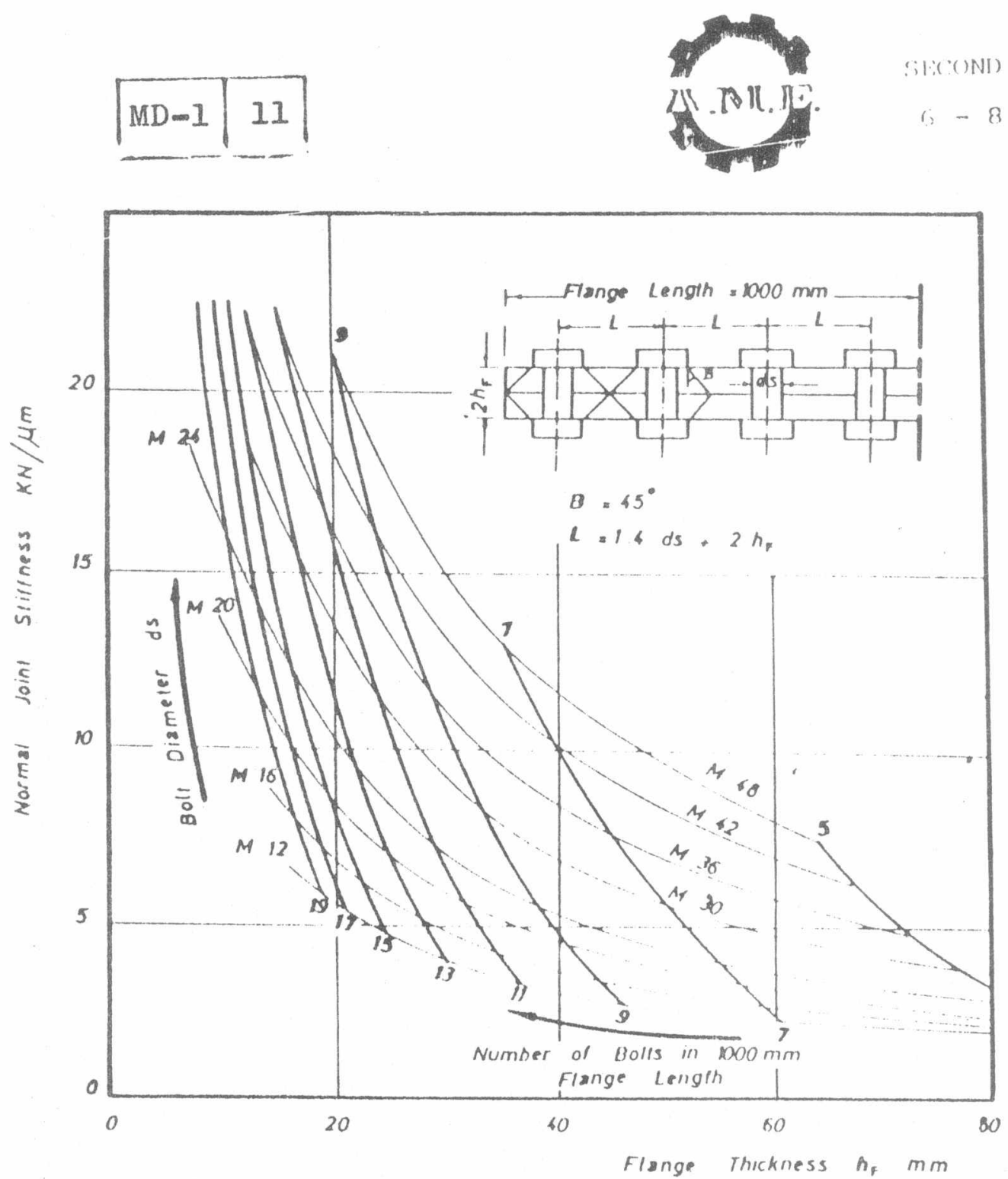

Fig:(7) Design Disgram of the Calculsted Joint spillness w. I. she Design Parsmaters. 
